\title{
MEDIAÇÃO DO DESIGN NO PROCESSO DE APRENDIZAGEM NA TERCEIRA IDADE: REPRESENTAÇÕES E RELACIONAMENTOS NA UNITI/UFMA
}

Bruno Serviliano Santos Farias

Universidade Federal do Maranhão

brunoserviliano@gmail.com

Andréa Katiane Ferreira Costa

Universidade Federal do Maranhão

andrea.katianefc@gmail.com

Arthur Marques

Universidade Federal do Maranhão

arthurgarre@gmail.com
Ana Luiza Lima Rodrigues

Universidade Federal do Maranhão analuizalimarodrigues@gmail.com

Raquel Gomes Noronha

Universidade Federal do Maranhão raquelnoronha79@gmail.com

Márcio James Soares Guimarães

Universidade Federal do Maranhão

falecommg@gmail.com

Resumo: Este trabalho faz parte do Projeto de pesquisa "Mediação do design no processo de aprendizagem na terceira idade" desenvolvido pelo NIDA - Núcleo de Pesquisa em Imagens, Design e Antropologia, do curso de Design, da UFMA - Universidade Federal do Maranhão. Este segmento da pesquisa se ocupa em analisar o relacionamento e as relações dos alunos da Universidade da Terceira Idade da UFMA. Para tal, foi empregada a pesquisa etnográfica e as estratégias de coleta de dados: observações em aulas e entrevistas com os docentes. A conclusão da investigação aponta para três pilares que sustentam as relações e animam as representações na terceira idade: qualidade de vida, amizade e busca de informações. Tais questões possuem desdobramentos nas estratégias de ensino que o design pode se apropriar para desenvolver intervenções com o intuito de melhorar a qualidade do ensino na terceira idade.

Palavras-chave: Representações Sociais, Processo de Aprendizagem, Terceira Idade.

\begin{abstract}
This work is part of research project "Design Mediation in the learning process in old age" developed by NIDA - Research Center for Images, Design and Anthropology, course design, UFMA. This segment of the research is concerned with analyzing the relationship and the relationship of students from the University of the Third Age UFMA. For this, we used ethnographic research with observations in lessons, interviews with teachers. The conclusion of the research points to three pillars that sustain the relationship and that animate the representations in the elderly: quality of life, friendship and search for information. Such questions have developments in teaching strategies that design can be appropriate to develop interventions in order to improve the quality of education in old age.
\end{abstract}


Keywords: Social Representations, Learning Process, Seniors

\section{INTRODUÇÃO}

Este trabalho faz parte do Projeto de pesquisa "Mediação do design no processo de aprendizagem na terceira idade" desenvolvido pelo NIDA - Núcleo de Pesquisa em Imagens, Design e Antropologia, do curso de Design, da da UFMA Universidade Federal do Maranhão. Este segmento da pesquisa se ocupa em analisar o ambiente de ensino da UNITI - Universidade Integrada da Terceira Idade da UFMA, partindo da observação das aulas, e entrevistas com os docentes, a fim de poder contribuir com o projeto para a terceira idade.

A UNITI/UFMA é um espaço onde são desenvolvidas ações educativas baseadas na promoção dos idosos, voltadas para fatores de socialização, psicológicos, comportamentais e emocionais que buscam motivações e interesses para esse público. $\mathrm{O}$ ambiente de ensino em foco tem como proposta um espaço interativo para o convívio, a autodescoberta, compartilhamento de experiências, sentimentos e a preparação para viver bem a velhice tanto no contexto social quanto no familiar.

$\mathrm{O}$ design pode contribuir com os processos de aprendizagem na terceira idade desenvolvendo artefatos didáticos adequados, mediando a relação ensinoaprendizagem, mapeando as facilidades e dificuldades da aprendizagem nesta fase de vida e gerando um ambiente pedagógico mais seguro e eficiente. Tais intervenções envolve a investigação das barreiras de aprendizagem bem como os fatores emocionais, ao analisar as experiências dos alunos e seu grau de participação nas aulas, assim como entender os aspectos emocionais e o impacto que causam no ensino.

O objetivo deste trabalho é compreender o que se entende por velhice e terceira idade, quais são os impactos dessa fase de vida para os próprios alunos e familiares e como isso se relaciona diretamente com o ambiente da UNITI/UFMA e o desempenho dos alunos nesta instituição, com a finalidade de perceber as relações dentro desse meio (entre discentes, alunos e professores ou entre os alunos e a própria figura da instituição), buscando possibilitar um embasamento, em nível psicológico e de relacionamento, para desenvolver projetos relacionados a questões como o ambiente e estratégias de ensino, ou quaisquer projetos futuros relacionados à educação para idosos.

\section{TRANSFORMAÇÕES DO CONCEITO DE VELHICE E O ENSINO NA TERCEIRA IDADE}

$O$ processo de envelhecimento constitui uma preocupação mundial e várias pesquisas e políticas públicas estão sendo realizadas com o intuito de gerar qualidade de vida. Entende-se a velhice como uma faixa da população a partir dos 60 anos que atualmente está em crescimento, em torno de 3,5\% ao ano, segundo o IPEA. Comparando as gerações de outras épocas percebe-se que a carga de trabalho é distinta das condições oferecidas às últimas duas gerações.

Segundo dados oficiais, comenta Shiraiwa (2008, p. 64), - IPEA e IBGE, com o aumento da expectativa de vida e o declínio da taxa de natalidade, a pirâmide populacional brasileira apresentou uma modificação, ocorrendo um estreitamento na base e alargamento no meio e o topo, quando comparados a outras épocas. Assim, continua a autora, "para o ano de 2050 estima-se uma população de 34,3 milhões de idosos (13,2\% da população) no país" e, nessa perspectiva, explica Shiraiwa (2008, p. 
64), "em 2051 o Brasil pertencerá ao grupo dos 10 países com maior população de pessoas com 60 anos ou mais em termos absolutos, que juntos representam $62,9 \%$ da população idosa mundial". Nesse contexto, o tema vem ganhando cada vez mais espaço não só no âmbito da pesquisa acadêmica, uma vez que afetará a economia de vários países e a qualidade de vida de milhões de pessoas em todo o mundo.

Para esse estudo é importante primeiramente listar as diferenças entre os termos "velhice" e "terceira idade" e os impactos que estas denominações podem causar na percepção cultural das pessoas a respeito desta fase da vida. Segundo Silva (2008) o surgimento da velhice e da terceira idade pode ser entendido como resultante de um processo complexo, que envolve a convergência de discursos políticos, práticas sociais, interesses econômicos e disciplinas especializadas (como a medicina, a antropologia, a psicologia, entre outros). É válido destacar que o primeiro dos termos listados a ser utilizado pela sociedade foi a "velhice". Dois fatores foram determinantes para o surgimento desse conceito: a formação de novos saberes médicos que investiam sobre o corpo envelhecido e a institucionalização das aposentadorias. Quanto à medicina, Laslett (1991) destaca a importância da metáfora da velhice para o imaginário cultural, cuja principal consequência foi produzir a associação entre velhice e doença.

O surgimento da expressão "terceira idade" é considerado, pela literatura especializada, uma das maiores transformações por que passou a história da velhice em decorrência da sensibilidade investida sobre esta fase da vida, o que permitiu uma profunda inversão de valores relacionados a ela como: decadência física e invalidez, momento de descanso e quietude na qual imperavam a solidão e o isolamento afetivo que foi ressignificado para o momento do lazer, propício à realização pessoal (Silva, 2008). Relacionado a este conceito de "terceira idade", Blaikie (1999) destaca a teoria da atividade, que supunha que um envelhecimento positivo poderia ser atingido se os sujeitos se mantivessem ativos, conservando os mesmos hábitos da vida adulta e desempenhando papéis sociais relevantes.

Quanto à institucionalização da aposentadoria, que para Silva (2008) foi fruto do processo de industrialização e envelhecimento das gerações de operários. A velhice destes trabalhadores foi assimilada à invalidez, ou seja, incapacidade de produzir (deste ponto de vista, a velhice passou a ser confundida com todas as formas de invalidez que atingiam a classe trabalhadora). Para Bandura (1986) o funcionamento competente de um indivíduo na interação com o ambiente não é só uma questão de saber o que fazer, mas envolve também crenças sobre a sua autoeficácia. No que diz respeito ao idoso e aos diversos estigmas sociais relacionados a esta fase da vida, a crença em sua eficiência é uma questão delicada ligada às suas noções pessoais a respeito de si mesmo, à opinião da família a respeito deste idoso e ao processo de socialização.

Tendo como pressupostos tais questões, como o aspecto fisiológico do processo de envelhecimento, o aspecto mercadológico e institucionalização da aposentadoria (por idade ou por tempo de serviço) e o aspecto social dessa nova categoria de cidadão, surgiram as Universidades da Terceira Idade. A primeira foi inaugurada em 15 de maio de 1973, na cidade de Toulose (França), destinada a promover o ensino e a pesquisa, fundada pelo professor de Direito Penal Pierre Vellas (FRUTUOSO, 1999). Seus princípios e objetivos, segundo Peixoto (1997), consideravam os níveis pessoais e sociais, visando à qualidade de ensino, à extensão das suas atividades (FRUTUOSO, 1999). 
O professor de direito ao fundar a primeira Universidade da Terceira Idade nos permite refletir sobre várias questões. Talvez a principal seja a nova percepção sobre a terceira idade, que descortina o idoso a partir de suas garantias legais, como qualquer outro cidadão e assim pode-se pensar em como melhorar sua qualidade de vida.

O Brasil também tem se preocupado com essa temática e passou a promover várias ações no sentido de valorizar essa faixa de idade. Em 2003 foi sancionado o Estatuto do Idoso com o objetivo de ampliar os direitos e a qualidade de vida dos cidadãos com idade acima de 60 anos, o que inclui ações efetivas tanto do Estado, como também da sociedade, que tem responsabilidades inalienáveis quanto à vida dos brasileiros que envelheceram (SHIRAIWA, 2008).

Antes disso, o país inaugurou as primeiras Universidades da Terceira Idade na década de 1980, mas foi só na década seguinte que essa abordagem se espalhou pelas universidades brasileiras. Os programas brasileiros vão ao encontro das propostas das Assembleias realizadas pela ONU (1982 e 2002), entre elas a integração dos idosos na sociedade, garantia dos seus direitos, exercício da sua cidadania e a participação de toda a sociedade (Cuba, 2015).

Veras (2007) explica que as universidades brasileiras são instituições públicas que atualmente possuem recursos para atender às necessidades da população idosa, por sua estrutura propiciadora de atividades de assistência, ensino, atividades culturais e lazer, daí o fato dos projetos da terceira idade surgirem primeiramente nessas instituições e não no setor privado.

São Luís também possui uma universidade da terceira idade. Desde 1995, através da parceria entre as Universidades Federal e Estadual do Maranhão, do Serviço Social do Comércio e da Secretaria de Planejamento, Orçamento e Gestão do Maranhão, foi criado o Projeto UNITI que representa, hoje, um espaço para ampla repercussão social, tem como objetivo oferecer à população da melhor idade a prática de atividades que lhes possibilitem fortalecer a participação social e política, assumir conscientemente o processo de envelhecimento e gozar de pleno exercício de sua cidadania, criando condições para o resgate da autoconfiança e da autoestima.

\section{RELACIONAMENTO NA TERCEIRA IDADE}

Primeiramente é válido destacar que as relações familiares e não-familiares são básicas para a socialização e desenvolvimento de pessoas mais velhas (Vega, 1992). Segundo Coll, Marchesi e Palácios (2004), os netos têm diversos significados para os avós, entre eles a possibilidade de vê-los como uma fonte de continuidade e de renovação biológica, ou ainda, a oportunidade de exercer novos papéis sociais e emocionais, o que nos possibilita pensar a respeito da vontade desses idosos de se sentirem úteis e notados por seus familiares, estimulando sua autoeficácia. Tal fato nos leva à outra questão: o apoio que esses idosos encontram na família para práticas sociais e de aprendizagem no ambiente de ensino.

Com relação ao apoio dos familiares às práticas socioculturais dos idosos, podemos citar uma pesquisa realizada por Carneiro e Falcone (2004), sobre as capacidades e deficiências em habilidades sociais na terceira idade na Universidade Aberta da Terceira Idade da Universidade do Estado do Rio de Janeiro (UnATI), projeto semelhante à UNITI da UFMA. Comparar as duas instituições pode ajudar a compreender melhor o ambiente e as relações. A pesquisa visou a identificar níveis de habilidades sociais de 30 estudantes idosos (selecionados de maneira aleatória) por 
meio de entrevista estruturada composta de 32 itens com perguntas abertas e semiabertas, com o objetivo de conhecer como o indivíduo interage em diferentes contextos sociais. Para análise destas respostas, duas foram as categorias criadas:

- Os sujeitos adotaram padrão de esquiva ou conseguiram enfrentar a situação de forma pouco ou nada habilidosa socialmente e;

- Os sujeitos que conseguiram enfrentar a situação de forma socialmente habilidosa.

As respostas obtidas nas entrevistas dos 30 sujeitos da amostra apontaram que, dos 14 itens em que os sujeitos explicavam como seria o seu desempenho na situação social, oito estão na categoria a), e seis encontraram-se na categoria b). Como resultados, foi possível admitir que os participantes deste estudo apresentaram uma variedade de habilidades sociais importantes para a aquisição de redes de apoio social (por exemplo, iniciar e encerrar conversação, fazer pedidos quando não há conflito de interesses, fazer e receber elogios, cumprimentar as pessoas, expressar opiniões pessoais, expressar sentimentos positivos e fazer perguntas). Essas habilidades são necessárias para iniciar e manter interações sociais agradáveis, por outro lado, as situações sociais em que a maioria dos sujeitos apresentou deficiências em desempenhar adequadamente foram: saber fazer um pedido adequadamente, mesmo quando há conflitos de interesses; apontar um comportamento de alguém que está incomodando; recusar pedido não razoável; responder a críticas adequadamente e lidar com alguém que manifesta hostilidade.

A partir destas observações, é interessante citar que segundo Bedell \& Lennox (1997), para interagir socialmente de modo efetivo, o indivíduo deve ser capaz de selecionar de forma acurada informações úteis e relevantes de um contexto interpessoal e de usar essa informação para determinar o comportamento apropriado dirigido à meta e executar comportamentos, verbais e não verbais, que maximizem a probabilidade de alcançar a meta, mantendo, ao mesmo tempo, boas relações com os outros. Para Matos (1997), as carências de habilidades sociais provocam dificuldades em situações interpessoais, tais como estabelecer novas amizades, aceitar críticas, lidar com provocações, pedir ajuda, resistir à pressão dos pares (familiares), entre outras. Relacionando a teoria com os dados obtidos na pesquisa, é possível observar que os resultados foram condizentes com os aspectos apontados por Matos (1997) como característicos do indivíduo que possui dificuldades em situações interpessoais, o que nos possibilita relacionar tais dados com os requisitos para uma interação social efetiva defendidos por Bedell \& Lennox (1997). Posterior a estas colocações, é válido citar ainda que, para Freire (2000) o aperfeiçoamento das habilidades sociais é uma das estratégias para atingir a velhice bem-sucedida.

Pode-se admitir então, que a teoria relacionada às habilidades sociais na terceira idade, ressalta a importância destas uma boa velhice, e elenca ainda possíveis consequências caso elas não aconteçam. O que se relaciona de maneira condizente aos resultados obtidos na pesquisa feita por Carneiro e Falcone (2004) e os resultados previamente listados neste artigo.

Skinner e Vaughan (1985) afirmam que além de aspectos relacionados à saúde, como ouvir bem e se movimentar de maneira eficiente, outras questões como as relações sociais podem se esvair no processo de envelhecimento, principalmente por falta de interlocutores. Para Carneiro e Falcone (2004) a expectativa de autoeficácia na 
terceira idade é muito pequena, uma vez que as pressões sociais são muito fortes no que tange às incapacidades atribuídas a essa fase da vida, sendo assim, a possibilidade de evidenciar esta inserção social certamente reforça as noções de autoeficácia destes idosos, consequentemente, estas representações são um sinal de convívio social eficiente, como uma certificação.

\section{MÉTODO DA PESQUISA}

Para o desenvolvimento deste artigo foi realizada uma revisão bibliográfica sobre psicologia do desenvolvimento com foco na terceira idade, relações e capacidades ou deficiências em habilidades sociais também na terceira idade. Com base na revisão bibliográfica foi realizada uma pesquisa de campo. Para tanto, nessa primeira fase da realizamos uma pesquisa etnográfica com observações em sala de aula e entrevistas com os professores.

Para tomada de decisão quanto às disciplinas que participariam do processo de observação, levou-se em consideração aspectos como a importância em avaliar as relações de ensino dos alunos idosos, o que nos levou a selecionar disciplinas teóricas, e o impacto positivo que a prática de atividades físicas tem no processo de envelhecimento, resultando na observação também de disciplinas práticas. Devido a distribuição dos horários, as disciplinas teóricas (Noções básicas de gerontologia; Lazer e Turismo; Reeducação alimentar; Fitoterapia; Psicologia na terceira idade; Concentração e Memória; e Nutrição) ficaram às segundas e quartas, e as práticas (Movimentos e ritmos e Yoga) às terças e quintas.

Foram observadas três semanas de aula do mês de novembro, final do ano letivo, dessa forma as relações professor-aluno e entre alunos já estavam consolidadas, com rotinas de ensino, convívio social, assimilação do vocabulário da disciplina e familiaridade com as atividades empregadas. Depois foram realizadas entrevistas semiestruturas com professores selecionados tendo como critério a disponibilidade dos docentes que ministravam as disciplinas elencadas para análise. Buscamos compreender as noções de relacionamento no ambiente da UNITI/UFMA, entre alunos, com professores e com a instituição, suas habilidades sociais e como os alunos se portavam em sala de aula. Como resultado, dos registros da observação e da transcrição das entrevistas, foi possível elaborar uma "nuvem de palavras" com os termos mais recorrentes desse tema nas observações e entrevistas (imagem 1).

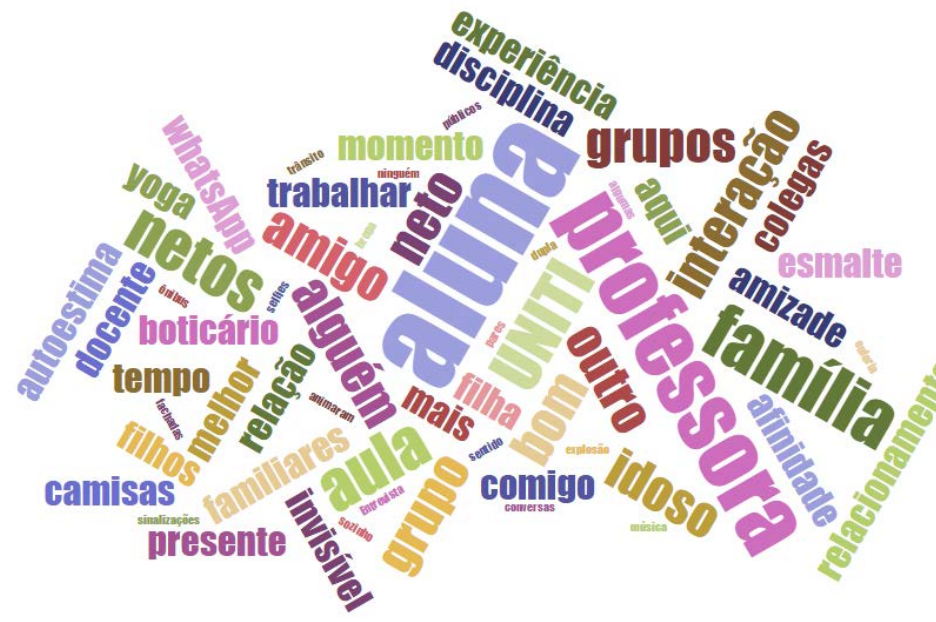

Imagem 1- Nuvem de Palavras

Fonte: resultado da pesquisa etnográfica, São Luís, 2016. 
Mediada por essa nuvem de palavras percebemos que algumas questões se sobressaem mais do que outras. Questões relacionas à família, como "familiares", "netos", "filhos" e "família"; questões envolvendo relacionamento dentro do ambiente da UNITI/UFMA, como "whatsapp", "colegas", "afinidade", "relação", "alunos" e de representações relacionadas a este ambiente, como "camisas", a palavra "UNITI" em evidência. Dentre todas estas palavras é possível observar que a de mais destaque é "alunos", o que nos possibilita admitir que os alunos da instituição são o ponto central entre as questões de relacionamento na UNITI. Baseado nessas relações que se elaborou uma análise desses grupos.

\section{DISCUSSÕES SOBRE AS REPRESENTAÇÕES SOCIAIS NA UNITI}

Segundo dados da própria UNITI, sobre o perfil dos alunos de 2013 , cerca de $90 \%$ dos alunos regularmente matriculados têm entre 50 e 70 anos. Há predominância de mulheres, mais de $90 \%$, e de religiosidade cristã, mais de $97 \%$. Cerca de $12 \%$ ainda trabalha e o mesmo percentual se refere ao que moram sozinhos. Mais da metade dos pesquisados afirmaram que se sentiam sozinhos, outros $50 \%$ afirmam possuir algum tipo de doença. Com relação à escolaridade, um quarto dos alunos não terminaram o ensino médio, metade terminaram o ensino médio e $15 \%$ concluíram o curso superior.

As expectativas ao participarem do projeto da terceira idade são as mais diversas: $37 \%$ declararam que esperam melhorar de vida; $34 \%$ desejavam fazer novas amizades; e $25 \%$ buscavam informações. Tais questões impactam nas representações e nos relacionamentos.

Observou-se que os pilares, qualidade de vida, amizade e busca de informações representam bem os tipos de sentimentos que os idosos têm ao procurarem o projeto de terceira idade da UFMA. Vale ressaltar que representação aqui é empregada no sentido de um produto da mente, conteúdo do que é apreendido pelos sentidos, a imaginação, a memória ou o pensamento se cristalizando em uma palavra ou gesto, impregnando nossas relações, como um sistema de valores.

Melhora da qualidade de vida é uma representação que se origina com novos saberes na área de saúde. Metade dos alunos relatou que possuem algum tipo de doença. Por isso, a UNITI oferece aulas de nutrição, gerontologia e psicologia na terceira idade. A preocupação com a qualidade de vida não se restringe nos aspectos clínicos, se desdobra nas transformações sociais nas quais há um investimento na terceira idade, invertendo alguns valores como decadência física, invalidez, descanso e isolamento afetivo para uma época de lazer, propício à realização pessoal, baseada na teoria da atividade, já citada. Em uma das entrevistas uma professora comentou:

É justamente mostrar para o idoso que embora ele tenha que se adaptar, porque se exige uma adaptação, porque eles vêm de uma vida muita ativa, onde eles produziram no mercado, eles têm que superar muitos preconceitos, muitos estereótipos relacionado à velhice e mostrar para eles que eles têm essa capacidade, essa potencialidade e ainda continuar se desenvolvendo, que a vida não para na velhice. Ser velho não é você ficar sentado inativo esperando a morte chegar, o envelhecer, que a gente fala muito nisso, o envelhecer é a atividade, é o verbo, é a ação, é envelhecer vivendo, é esse gerúndio, fazendo, acontecendo, produzindo. Na verdade, é isso, não é o findar, é o continuar. 
A amizade, ou o sentimento de acolhimento, oposto ao isolamento afetivo, é a segunda representação de sustentação do ambiente da UNITI/UFMA. O relacionamento, ou a procura pelo envolvimento social talvez seja o traço principal desse público e desse projeto. Apenas $12 \%$ declararam que moram sozinhos, no entanto a metade declarou que se sente isolado. $O$ que nos permite afirmar que solidão não é a falta de companhia. Tal afirmação nos sugere que mesmo morando com seus parceiros, amigos e familiares não há uma identificação, uma cumplicidade. O que existe, supostamente, é a divisão do mesmo espaço, não o compartilhamento das experiências, ou até mesmo algum tipo de violência doméstica, como relatada por alguns professores.

A demanda pelo projeto da terceira idade encontra-se aqui como uma justificativa social, não como uma mítica comunidade ideal onde todos possuem opiniões e gostos semelhantes, como afirmaria Moscovici (2007, p. 104), para evitar conflitos, mas de relações significativas, na qual compartilham linguagens, valores e memórias.

A trama social, fortalecida pelos significados compartilhados, tornou a UNITI uma comunidade pública, em oposição a espaços privados, como carros e shoppings. Os discentes do projeto da terceira idade interagem através da linguagem, valores e memórias por um longo período de tempo, em uma prática de solidariedade social. Tais práticas admitem várias tonalidades, como relações paternas, fraternas e íntimas e se tornam abertas à novidade.

O vínculo social prolongado, ao longo do ano, contribui para a criação de uma entidade, delimitada pelo projeto da terceira idade, com turmas de disciplinas, equipes de trabalho, compartilhando valores. Tal fato pode ser constatado pelo uso de tecnologia da informação e camisas. Em uma das entrevistas, uma professora apontou que:

Elas nunca vêm só, trazem ou vêm com a vizinha por exemplo. Elas formam grupos, marcam encontros fora daqui, saem, aumenta o círculo de amizades. Às vezes eles chegam só e saem com muitos amigos. Elas têm grupos no WhatsApp e acabam proporcionando outras experiências de lazer além das que a UNITI proporciona.

Outra indicação dos valores compartilhados é uso de camisa com a marca da UNITI. Fato percebido, mesmo não sendo obrigatório, muitos alunos fazem questão de comprar e utilizar diariamente nas aulas.

Baseado em tais índices, pode-se afirmar que a instituição de ensino se tornou um local seguro, familiar, permitindo comportamentos e relações que não seriam possíveis em outros ambientes. Os idosos do projeto podem exercer suas identidades e ter novos tipos de relacionamentos, mesmo os conflitantes, como saber fazer um pedido adequadamente mesmo quando há conflitos de interesses; apontar um comportamento de alguém que está incomodando; recusar pedido não razoável; responder a críticas adequadamente e lidar com alguém que manifesta hostilidade, situações típicas do dia a dia. Assim, é possível estimular noções de autonomia que podem extrapolam esse ambiente de ensino e contribuir para todas as relações pessoais dos discentes.

Por outro lado, o apego que muitos estudantes têm com a instituição de ensino nos fez refletir sobre o relacionamento familiar. Em algumas situações foram percebidos tensões entre as relações familiares e as relações sociais no ambiente do projeto da terceira idade, como comentado por uma professora: 
A falta de valorização dentro da família. São trabalhos gerais, não só aqui dentro... aqui é um espelho... essa falta de respeito, com a família. A carga dos filhos que não entendem que eles são mais uma família, que eles têm que assumir, mas deixam os netos. Muitas vezes eles não vêm, ficam triste porque estão cuidando do netinho porque as vezes eles têm uma programação para ir... ah não fui porque estava cuidando do neto que minha filha deixou comigo.

É comum e legítimo idosos preocuparem-se com a família e até mesmo assumirem a responsabilidade de sustentá-la. No entanto, em decorrência disso, eles se ausentam das aulas para cumprir afazeres relacionados ao âmbito familiar, como cuidar dos netos, e com isso muitos acabam por desistirem do projeto da terceira idade.

Não há dúvidas que o contexto social exerce influência. São Luís, assim como várias cidades do Nordeste e inúmeras cidades do Brasil, apresentam graves indicadores sociais como: concentração de renda, baixa escolaridade, acesso à saúde deficitária, etc. Nesse sentido, as representações familiares exercem uma importância capital sobre os idosos, principalmente quando eles não têm apoio familiar, como é o caso de muitos.

A falta de estímulo familiar agrava a ausência de alguns alunos no decorrer do período letivo, impactando na autonomia. Atrelado a isso, há ainda estigmas culturais sobre os idosos que não permitem que eles desenvolvam atividades sociais ou educacionais, agem como se estivessem encerrados o ciclo de vida. Tanto nas entrevistas com os professores como nos comentários dos alunos foram registradas atividades como viagens, visitas, comemorações. No entanto, os docentes recomendam não levarem os familiares e muitos discentes também preferem não convidá-los, alegando que alguns poderiam se sentir constrangido, deixar de aproveitar ou mesmo coagidos a não se divertirem.

Por outro lado, o isolamento afetivo dos laços familiares pode ser apontado também com a motivação de muito idosos em procurarem a UNITI, principalmente por atividades que envolvam convívio com pessoas.

Outra representação, com forte apelo simbólico, é provocada pela aposentadoria. A perda do vínculo profissional pode vir acompanhada por um sentimento de invalidez, incapacidade em uma lógica de produção. Nesse sentido, a busca por informação, capacitação, confia valores intelectuais que gera um sentimento de autoeficácia. Por isso, que a formatura neste ambiente é bastante valorizada pelos alunos e incentivada pelos professores e coordenadores da instituição, como um ritual de passagem, uma etapa cumprida.

Atividades de aspecto intelectual também são valorizadas pelos idosos por estimularem as noções de autoeficácia, assim, poder finalizar a conclusão deste ciclo com êxito, com beca, fotos, formatura e pompa representa um sentimento de ânimo e autorrealização para estes alunos.

\section{CONCLUSÃO}

Considerando o presente estudo uma etapa de um projeto maior, pode-se compreender diversas questões que estão envolvidas com as noções de relacionamento na terceira idade, tanto as capacidades em habilidades sociais quanto o valor associado as disciplinas e relação de professores e alunos estão relacionadas ao processo de envelhecimento e ensino na UNITI/UFMA. 
Para se obter tal compreensão foi necessário um longo levantamento bibliográfico do desenvolvimento psicológico na terceira idade, das habilidades sociais, e a importância do desenvolvimento e estímulo dessas habilidades, assim como a postura da sociedade com relação às pessoas mais velhas, crenças em suas capacidades e a consequente imposição da sociedade com relação às capacidades e atividades destinadas aos idosos.

Na pesquisa etnográfica foram observadas as aulas e a relação entre professor e aluno, bem como as possíveis identificações destes alunos. Suas posturas e desempenho foram analisados a partir de entrevista com professores, além das observações. Como resultado foi elaborado uma nuvem de palavras com a qual se pôde agrupar os temas relacionados.

O tema geral abordado neste artigo foi as noções de relacionamento no ambiente da UNITI/UFMA, que foi destrinchado em dois grandes polos, o que diz respeito aos relacionamentos (dentro e fora do ambiente da instituição), e o que diz respeito as representações relacionadas à instituição.

A interação social se mostrou bastante significativa para estes alunos, funcionando não apenas como um reforço para a frequência às aulas, mas também como o principal motivador da procura pela instituição de ensino. Sendo assim, as questões sociais se mostraram de extrema importância para o desenvolvimento de estratégias de ensino, assim como para a elaboração de possíveis materiais didáticos.

Nesse sentido, esse estudo se mostrou relevante para mapear estas questões de relacionamento e identificar sua importância para o possível desenvolvimento de materiais que visam auxiliar o processo de aprendizagem por parte destes idosos. Há várias questões que se pretendem aprofundar, bem como várias possibilidades em que o design pode intervir e contribuir para construir materiais didáticos, ou interferir na estrutura do ambiente, associados a interação com os alunos. Pretende-se assim, utilizar este estudo como base para quaisquer projetos que visem trabalhar diretamente com a rotina de interação e relacionamento no ambiente da UNITI/UFMA, que se mostrou bastante delicada e significativa no desenvolvimento deste projeto.

\section{REFERÊNCIAS}

BANDURA, A. Social foundations of thought and action: a social cognitive approach. Englewood Cliffs: Prentice Hall, 1986.

Bedell, J.R. \& Lennox, S.S. Handbook for communication and problem-solving skills training: A cognitive-behavioral approach. New York: John Wiley \& Sons. 1997.

BLAIKIE, Andrew. Ageing and popular culture. Cambridge: Cambridge University Press. 1999.

CARNEIRO, Rachel; FALCONE, Eliane. Um estudo das capacidades e deficiências em habilidades sociais na terceira idade. Psicologia em Estudo, Maringá, v.9, n.1, p. 119126, 2004.

COLL, Cesár; MARCHESI, Álvaro; PALÁCIOS, Jesus. Desenvolvimento psicológico e educação. Porto Alegre: Artemed, 2004.

CUBA, Conceição de Mara G. Braga. Guarnicê e cidadania na amizade dos idosos cariocas e ludovicenses. São Luis: Edufma, 2015. 
FRUTUOSO, D. A terceira idade na universidade. Rio de Janeiro: Ágora da Ilha. 1999.

LASLETT, Peter. A fresh map of life: the emergence of the third age. Cambridge: Harvard University Press. 1991

Matos, M.G. Comunicação e gestão de conflitos na escola. Lisboa: Edições FMH. 1997. Moscovici, Serge. Representações sociais: investigações em psicologia social. Petrópolis, RJ: Vozes, 2007.

SILVA, Luna Rodrigues Freitas. Da velhice à terceira idade: o processo histórico das identidades ao processo de envelhecimento. In: História, Ciência e Saúde. Rio de Janeiro, V. 15, N. 1, p. 155-168, jan-mar. 2008

SHIRAIWA, Juliana Couto Silva. 0 reconhecimento de pictogramas em interface gráfica digital pelo usuário idoso - o caso do Portal Pró-cidadão da PMF. (Dissertação) Mestrado. Universidade Federal de Santa Catarina, 2008, Florianópolis.

SKINNER, Burrhus Frederic; VAUGHAN, M. E. Viva bem a velhice: aprendendo a programar a sua vida. São Paulo: Summus, 1985. 